\title{
Laboratory Evaluation of Time-Domain Reflectometry for Bridge Scour Measurement: Comparison with the Ultrasonic Method
}

\author{
Xinbao Yu and Xiong Yu \\ Department of Civil Engineering, Case Western Reserve University, 10900 Euclid Avenue, Bingham 203C, \\ Cleveland, $\mathrm{OH}$ 44106-7201, USA \\ Correspondence should be addressed to Xiong Yu, xxy21@case.edu
}

Received 10 December 2009; Revised 28 March 2010; Accepted 6 May 2010

Academic Editor: Piervincenzo Rizzo

Copyright (๑) 2010 X. Yu and X. Yu. This is an open access article distributed under the Creative Commons Attribution License, which permits unrestricted use, distribution, and reproduction in any medium, provided the original work is properly cited.

Bridge scour is a major factor causing instability of bridges crossing waterways. Excessive scour contributes to their high construction and maintenance costs. Design of innovative scour-monitoring instrumentation is essential to ensure the safety of scour-critical bridges. The ability of real-time surveillance is important since the most severe scour typically happens near the peak flood discharge. A new scour-monitoring instrument based on the Time Domain Reflectometry (TDR) principle has been developed to provide real-time monitoring of scour evolution. A framework based on dielectric mixing model has been developed, which can be easily incorporated into an automatic analysis algorithm. This paper introduces a comparative study of TDR method and ultrasonic method for scour measurements. The results indicate that both TDR and ultrasonic methods can accurately estimate scour depth. TDR method, with the developed analysis algorithm, yields information on the river properties such as the electrical conductivity of river water and the density of sediments. TDR methods are also found less influenced by turbulence and air bubbles, both likely to occur during flood events.

\section{Introduction}

Bridge scour or bridge sediments scour refers to the lowering of the streambed around bridge piers or abutments. Typical types of scour include: (1) long-term degradation of the river bed, (2) general scour including contraction scour, and (3) local scour at the piers or abutments [4]. Among these types of scour, local scour is the most critical (Figure 1). Local scour is caused by the interference of piers and abutments with stream flow. It is characterized by the formation of scour holes surrounding bridge piers or abutments, and as a result, the support provided by the surrounding soils will be reduced.

Bridge scour poses a severe threat to bridge safety. Since 1970 over 1,000 bridges have collapsed with associated deaths due to bridge scour. Bridge scour is also a major factor contributing to the high construction and maintenance cost of bridges. Proper scour prediction is essential for an economical and safe design of bridge piers and abutments. Current scour design relies on the empirical scour prediction equations developed from laboratory data, which generally do not accurately predict the scour under field conditions [5]. This necessitates collecting scour data from the field to improve current scour prediction theory. Because scour can cause catastrophic failure of bridges without any prior warning such as signs of distress in the superstructure, realtime scour-monitoring systems are critical for providing realtime safety surveillance.

There are a few methods currently available for field scour measurements including yardstick, ultrasonic method, ground penetration radar, and fisher bulb [6]. Each method has shortcomings including: (1) most of the instrumentation is not sufficiently rugged for field applications. (2) most of these methods do not provide real-time monitoring of scour evolution in critical flood events. (3) these instruments are generally not automated requiring an appreciable amount of human involvement for signal interpretation [7].

Instruments based on Time Domain Reflectometry (TDR) overcome these shortcomings and have been used to monitor bridge scour. The potential use of TDR for bridge scour measurement has been explored by a few researchers. Dowding and Pierce [2] developed a TDR 


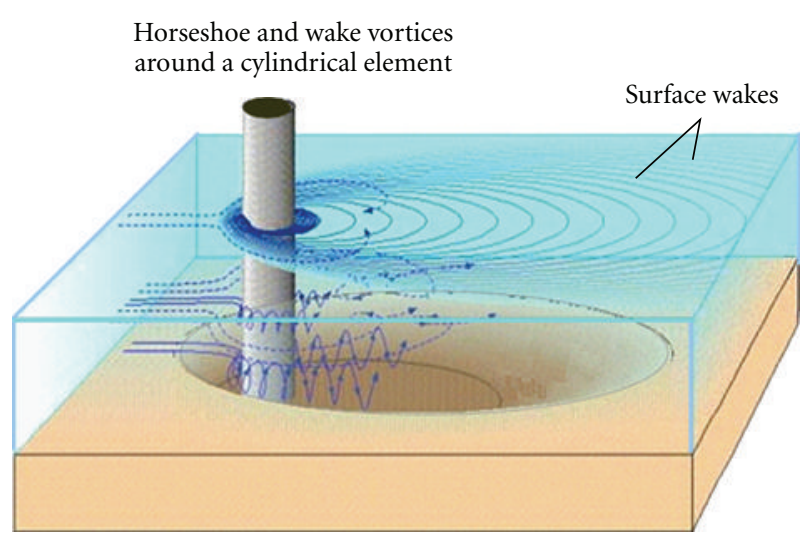

FIGURE 1: Schematic of local scour [1].

scour detection system that utilized small turbines installed along an electrical cable. The turbines would be successively exposed as scour developed. The torque generated by the turbine blades causes the shearing of cable, which can be detected by TDR method, and the scour depth is then estimated (Figure 2(a)). This system is not reusable due to the sacrificial characteristics of the detection cable. Yankielun and Zabilansky [3] also developed a TDR sensor by use of multiple steel pipes. Field evaluation showed that this probe was sufficiently rugged to resist floods and ice loading (Figure 2(b)). The major shortcoming of their design is that the two steel pipes were electrically shorted at the ends, which makes it difficult to develop an automatic signal interpretation algorithm. Efforts were made to improve signal analyses and with limited success [7].

The authors recently developed a new method of TDR scour signal analysis, which significantly simplifies the procedures of data processing and makes it possible to develop an automatic real-time scour surveillance system [8]. This paper briefly summarizes the principles of this TDR scour measurement system. Ultrasonic method has been chosen for comparison as it is currently the most popular fixed scour-monitoring device according to the survey conducted by Hunt [6]. In this study, the performance of TDR is compared with ultrasonic methods under laboratory simulated scour/sedimentation conditions. The TDR method was found to have accuracy equivalent to the ultrasonic method for scour depth determination. The TDR method has the advantage of being less influenced by factors such as air bubbles and suspended sediments which are likely to form due to turbulent flow conditions during floods.

\section{Principles of Time Domain Reflectometry and Ultrasonic Method}

2.1. Time Domain Reflectometry. Time Domain Reflectometry (TDR) technology was first utilized by electrical engineers to locate discontinuities in electrical cables. The application was later extended to measure material dielectric properties. The configuration of a typical TDR system is shown in
Figure 3. It generally includes a TDR device (pulse generator and sampler), a connection cable, and a measurement probe. The measurement probe is surrounded by the materials whose properties are to be measured. TDR works by sending a fast rising step pulse or impulse to the measurement probe and measuring the reflections due to the change of system geometry or material dielectric permittivity. A commercial TDR unit TDR100 by Campbell Scientific Inc. was used as the pulse generator and sampler. The device can generate a pulse output with a rising time of less than 300 picoseconds, amplitude of $250 \mathrm{mV}$, and duration of 14 microseconds. The probe used was the CS605 TDR moisture probe which consists of 3 rods, each $30 \mathrm{~cm}$ in length and $0.48 \mathrm{~cm}$ in diameter, with spacing between the outer rods of $4.5 \mathrm{~cm}$ [9]. The probe was connected to the TDR 100 by a $14 \mathrm{ft}$ long RG58 coaxial cable.

Figure 4 shows a typical measured TDR signal when the probe is installed in a uniform soil. The dielectric constant (which is generally referred to as apparent dielectric constant and is denoted as $K_{a}$ in this paper) and the electrical conductivity (denoted as $\mathrm{EC}_{b}$ in this paper) can generally be easily obtained from direct analysis of a TDR signal. The dielectric constant is related to the speed of electromagnetic waves in soils. The electrical conductivity is related to the rate of attenuation of the propagating electromagnetic wave. The dielectric constant is calculated by

$$
K_{a}=\left(\frac{L_{a}}{L_{p}}\right)^{2},
$$

where $K_{a}$ is the measured dielectric constant; $L_{p}$ is the physical length of probe embedded in soil; $L_{a}$ is called the apparent length as shown in Figure 4.

TDR measured dielectric constant is strongly related to the water content of soils, and various empirical relationships have been established to describe the correlation. Topp's equation (i.e., (2)) was developed from experiments on various types of cohesionless soils and is generally referred to as a "universal" equation:

$$
\theta=4.3 \times 10^{-6} K_{a}^{3}-5.5 \times 10^{-4} K_{a}^{2}+2.92 \times 10^{-2} K_{a}-5.3 \times 10^{-2},
$$

where $\theta$ is volumetric water content defined as percentage of the total volume that is occupied by water.

The electrical conductivity is calculated by

$$
E C_{b}=\frac{1}{C}\left(\frac{V_{s}}{V_{f}}-1\right)
$$

where $V_{s}$ is the source voltage. $V_{f}$ is the long-term voltage level. $C$ is a constant related to probe configuration, which can be obtained by theoretical analysis or by calibration against a reference technology such as an electrical conductivity meter.

The ability of TDR for scour-monitoring lies in the large contrast between the dielectric constant of water (around 81 ) and that of the air (1) or sediment solids (the dielectric 


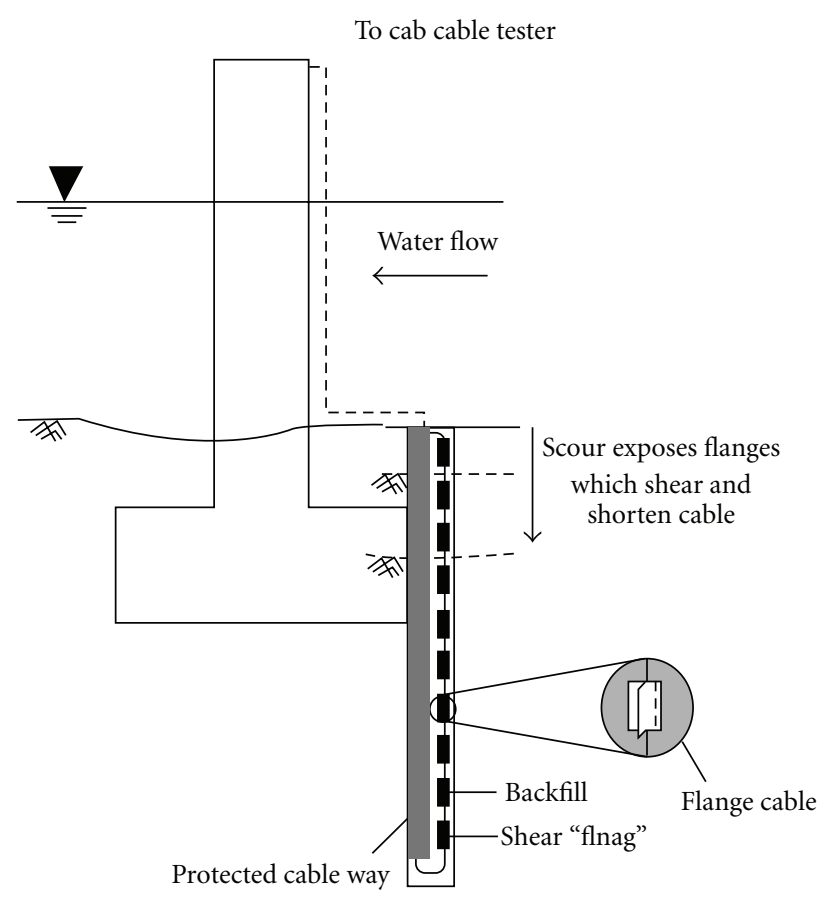

(a)

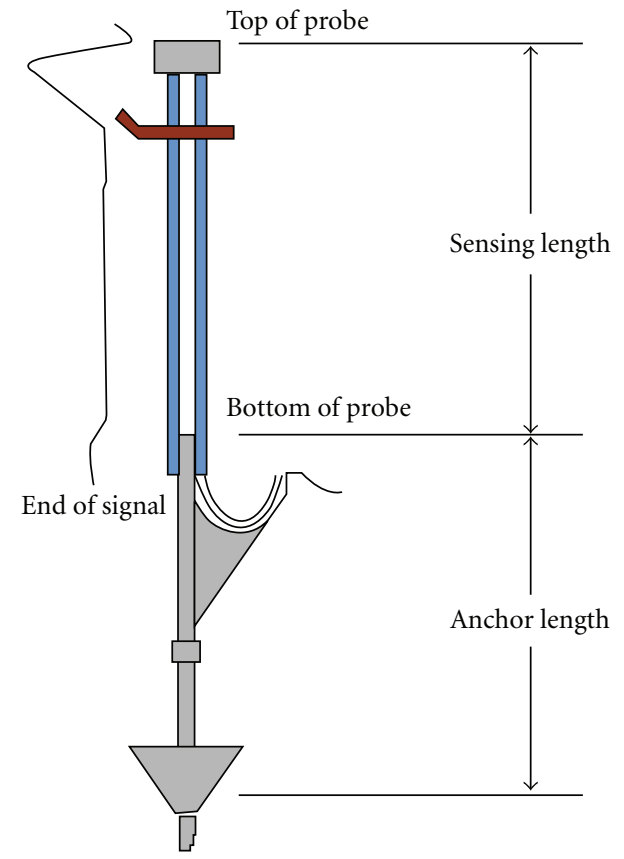

(b)

FIGURe 2: (a) TDR scour-monitoring system developed by Dowding and Pierce [2]; (b) schematic of the TDR scour system by Yankielun and Zabilansky [3].

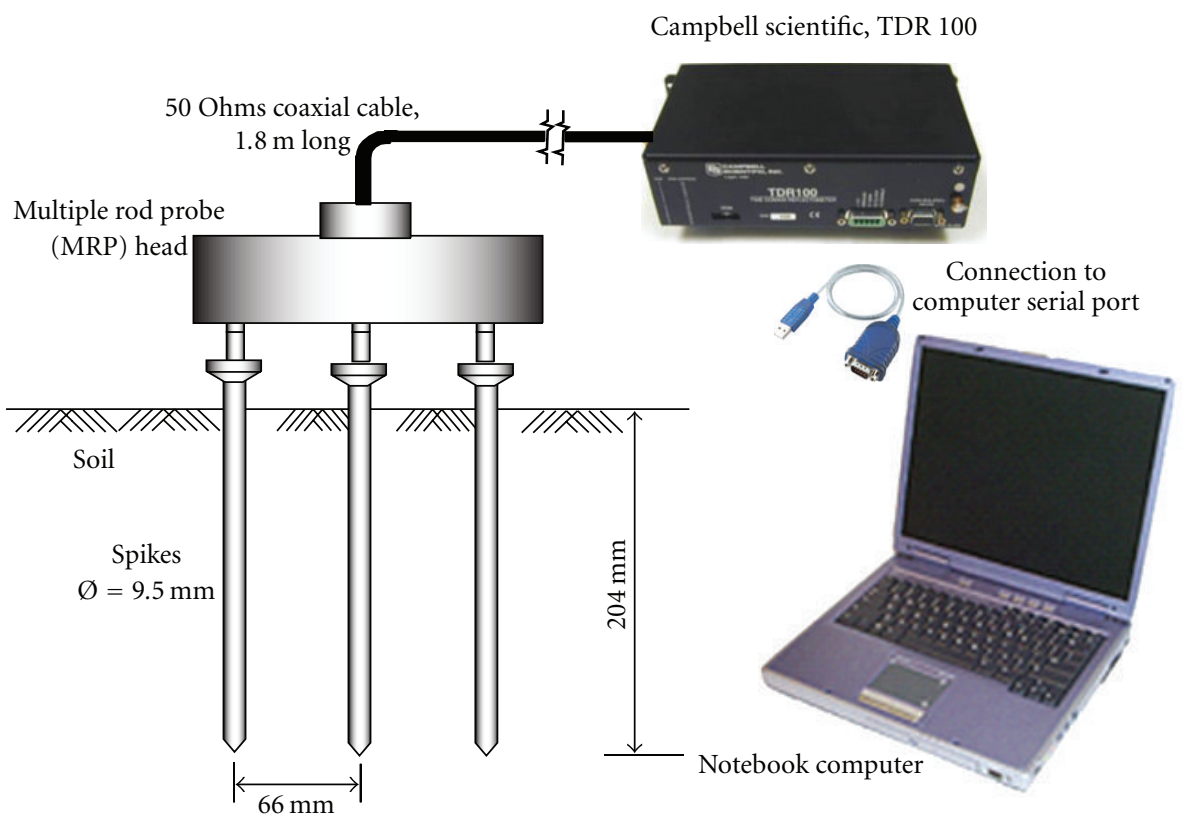

FIgURE 3: Schema of a typical TDR system.

constant for dry solids is between 3 and 7; that of saturated solids varies depending on the degree of saturation). Because of the large contrast in the dielectric properties, reflections will take place at the interfaces between material layers with different dielectric properties (including the air/water interface and the water/sediment interface) (Figure 5).
2.2. Ultrasonic Method. The configuration of a typical ultrasonic testing system is shown in Figure 6. The ultrasonic system used in this study includes the following components: a pulse generator by Panametrics-NDT Inc. (model: 5077PR), an ultrasonic transducer of $0.5 \mathrm{MHz}$ (PanametricsNDT, Waltham, MA, USA), and a PC oscilloscope 3402 


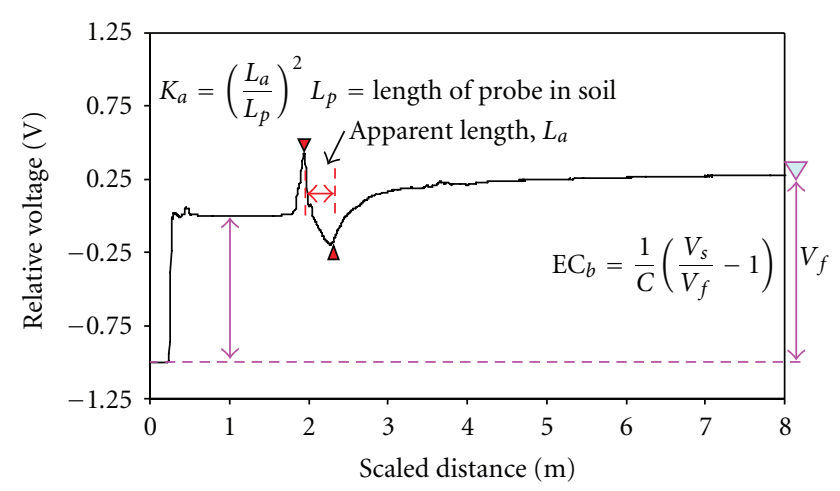

FIgURE 4: A typical TDR output signal.

(Pico Technology Ltd, St. Neots, United Kingdom). The ultrasonic system is set to work in the pulse-echo mode, where a single ultrasonic transducer serves as both transmitter and receiver. In the pulse-echo system, the transmitting transducer introduces a wide-band acoustic signal into the test object. The pulse propagates in the material and is scattered or reflected by the interfaces or inhomogeneities within the object. Because of the large contrast in acoustic impedance, the interface between water and sediment will cause a large amount of acoustic energy to be scattered or reflected. The reflections are picked by the receiving ultrasonic transducer. The returning signal can be displayed as a plot of amplitude versus time (referred to as A-scan). The depth of scour can be determined by determining the transit time required for receiving the echo reflections. A typical signal recorded during application of the ultrasonic method for scour measurement is shown in Figure 7. There are a few recent developments in ultrasonic technology, including a new testing method called direct-sequence, spreadspectrum, ultrasonic evaluation (DSSSUE), which is believed to have higher sensitivity and larger scan area compared with the traditional method. Details about ultrasound methods can be found in the work of Rens et al. [10].

\section{Theory and Application Procedures of TDR Scour Detection System}

Directly identifying the intermediate reflections at scour interface from a TDR signal can be very challenging. To overcome this difficulty, a new algorithm for TDR scour measurement has been developed by the authors of $[8,11]$. It utilizes the information of dielectric constant and electrical conductivity, which can easily be obtained from analyzing a TDR signal. The principles of this system are briefly described in the following context.

\subsection{Development and Validation of Mixing Formula for Bulk} Dielectric Constant. Applying the semiempirical volumetric mixing model [12] to layered media consisting of water and sediment, the following equation can be obtained:

$$
L_{1} \sqrt{K_{a, w}}+L_{2} \sqrt{K_{a, b s}}=L \sqrt{K_{a, m}}
$$

where $K_{a, w}$ is the dielectric constant of water; $K_{a, b s}$ is the dielectric constant of bulk sand (sand with water mixture); $K_{a, m}$ is the measured bulk dielectric constant; $L_{1}, L_{2}$, and $L$ are the thickness, of water layer, sand layer and the total thickness respectively (Figure 5).

Let the thickness of sediment $L_{2}$ be $x$, then the thickness of water layer $L_{1}$ is $L-x$. Substituting these into (4) and normalizing both sides by $\sqrt{K_{a, w}}$, the following equation can be obtained:

$$
\frac{\sqrt{K_{a, m}}}{\sqrt{K_{a, w}}}=\frac{x}{L}\left(\frac{\sqrt{K_{a, b s}}}{\sqrt{K_{a, w}}}-1\right)+1 .
$$

The equation indicates that square root of the measured bulk dielectric constant by TDR is linearly related to sediment layer thickness. The process of normalization also helps to reduce the potential effects of the measurements system on the results. On the other hand, when the scour depth is determined, the dielectric constant of bulk sediment layer, $K_{a, b s}$ can be determined as follows:

$$
K_{a, b s}=\left(\frac{L}{x} \sqrt{K_{a, m}}-\frac{L-x}{x} \sqrt{K_{a, w}}\right)^{2} .
$$

This can then be used to estimate the soil porosity and density using Topp's equation (2).

Figure 8 shows the measured $\sqrt{K_{a, m}} / \sqrt{K_{a, w}}$ ratio versus sediment thickness from experimental data on fine sand in tap water. Also shown in Figure 8 are theoretical predictions, where $\sqrt{K_{a, b s}}$ was estimated from Topp's equation using the density of sand layers from experimental records. The comparison shows that (5), which is based on the dielectric mixing formula, is valid for studying the layered scour/sedimentation process. As an additional comment, the dielectric constant of saturated sediment can also be estimated using a volumetric mixing model [12]:

$$
n \sqrt{K_{a, w}}+(1-n) \sqrt{K_{a, s}}=\sqrt{K_{a, b s}}
$$

where $K_{a, b s}$ is the dielectric constant of the saturated sand; $K_{a, w}$ is the dielectric constant of water; $n$ is porosity and $K_{a, s}$ is the dielectric constant of soil solid, typically in the range of 3-5 (an average value of 4 is used for $K_{a, s}$ in this study).

3.2. Development and Validation of Mixing Formula for Electrical Conductivity. Similarly, for a two-layered system made of water and saturated sediment, the mixing formula for electrical conductivity was found to be $[8,11]$

$$
\mathrm{EC}_{b, w} L_{1}+\mathrm{EC}_{b, b s} L_{2}=\mathrm{EC}_{b, m} L
$$

where $\mathrm{EC}_{b, w}$ is the electrical conductivity of water; $\mathrm{EC}_{b, b s}$ is the electrical conductivity of sand layer (sediment); $\mathrm{EC}_{b, m}$ is the measured bulk electrical conductivity; $L_{1}$ is the thickness of water layer, and $L_{2}$ is the thickness of sediment; $L$ is the total thickness.

Equation (8) can be normalized by dividing both sides by $E C_{b, w}$, that is,

$$
\frac{\mathrm{EC}_{b, m}}{\mathrm{EC}_{b, w}}=\left(\frac{\mathrm{EC}_{b, b s}}{\mathrm{EC}_{b, w}}-1\right) \frac{x}{L}+1 .
$$




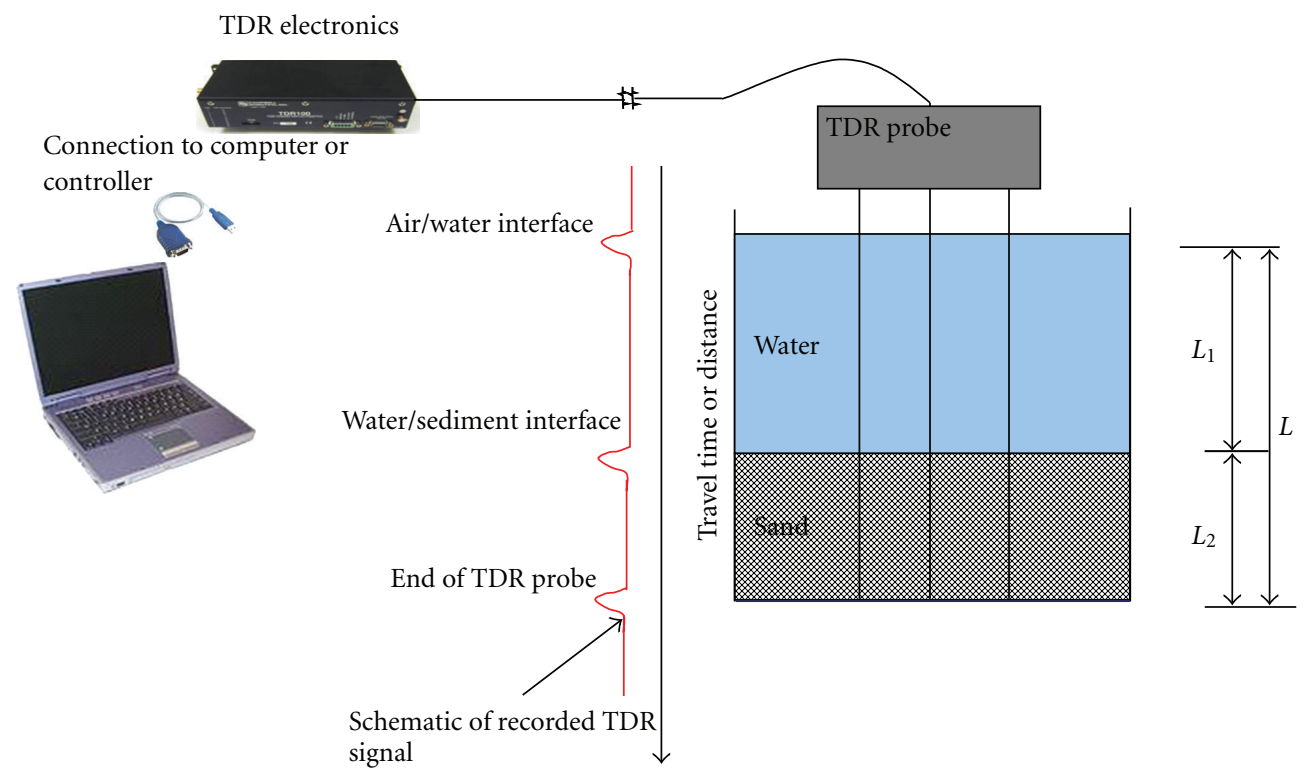

FIGURE 5: Schematic plot of TDR scour measurement principle.

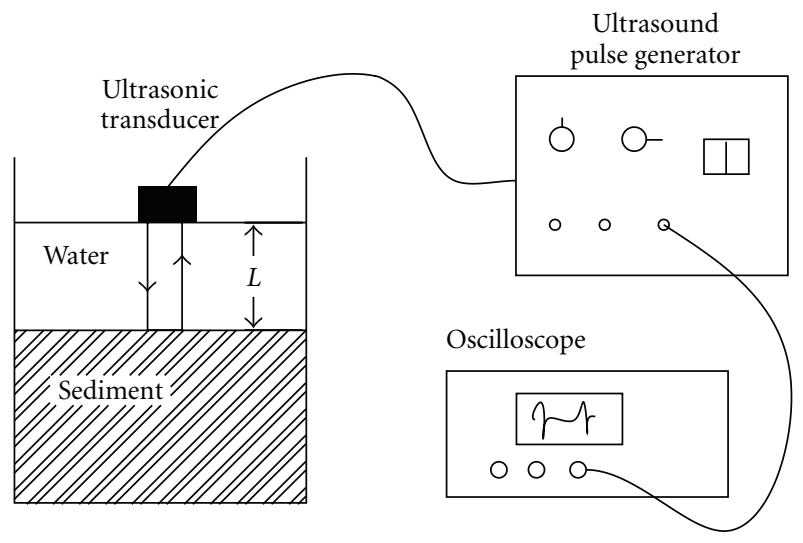

FIGURE 6: Schematic of a typical ultrasonic testing system.

Introducing the concept of formation factor by Archie [13], the following equation can be obtained:

$$
\frac{\mathrm{EC}_{b, b s}}{\mathrm{EC}_{b, w}}=\frac{1}{F}=n^{f}
$$

where $f$ is form factor, a value of 1.2 for $f$ was recommended for fine sand such as Nevada sand; $n$ is the porosity.

Substituting (10) to (9), we get

$$
\frac{\mathrm{EC}_{b, m}}{\mathrm{EC}_{b, w}}=\left(n^{f}-1\right) \frac{x}{L}+1
$$

Equation (11) shows that the measured electric conductivity normalized by the electric conductivity of water is approximately linearly related to the sediment thickness. Figure 9 compares (11) with experimental measurements. The comparison indicates that the mixing formula for the electrical conductivity of sediment system is valid.

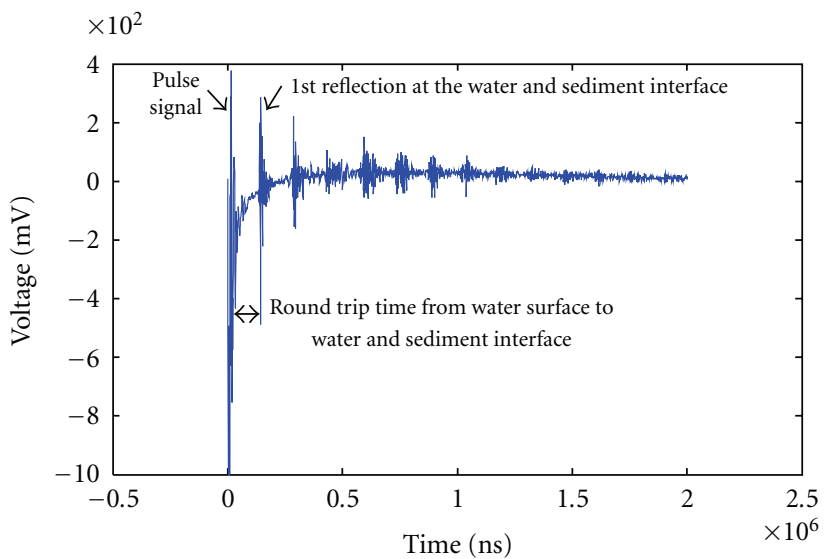

Figure 7: A typical ultrasonic signal.

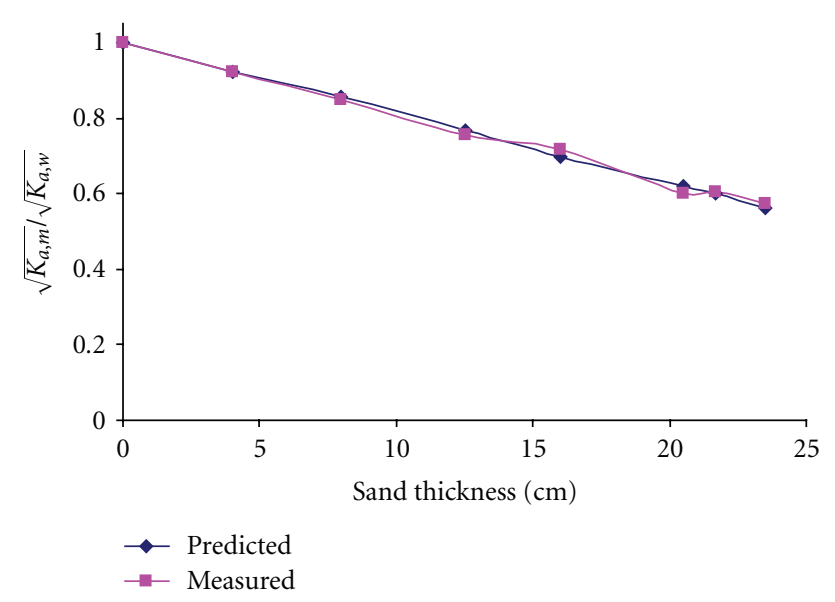

FIGURE 8: Measured and predicted relationship between $\sqrt{K_{a, m}} / \sqrt{K_{a, w}}$ and sediment layer thickness. 


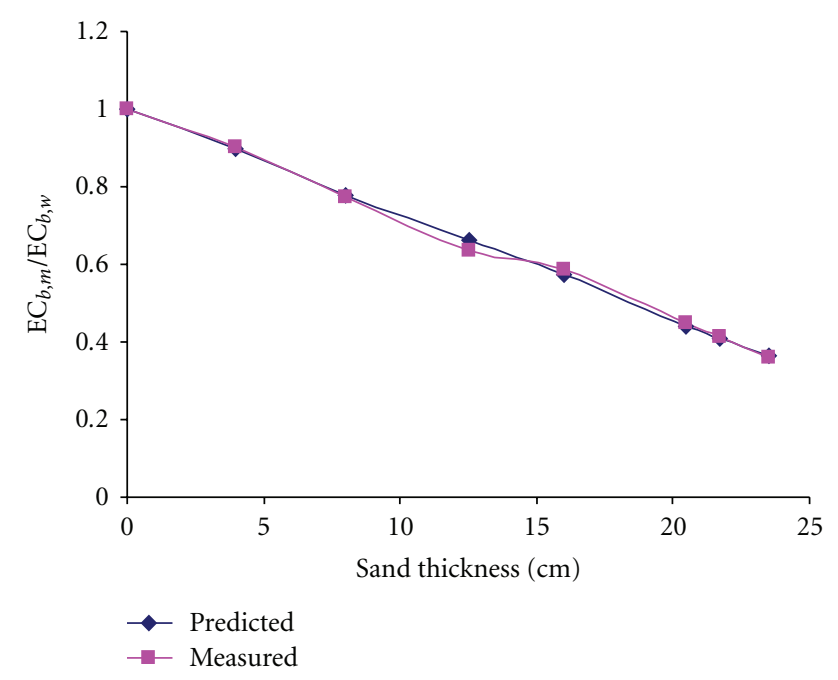

Figure 9: Measured and predicted relationship between $B C_{b, m} /$ $B C_{b, w}$ and sediment layer thickness.

3.3. Design Plot and Application Procedures of TDR for Bridge Scour Measurement. Procedures to apply the TDR algorithm were recently developed by the authors of $[8,11]$. They are based on two general linear relationships determined from experimental data collected on a few types of sediments (e.g., Figures 10(a) and 10(b)),

$$
\begin{aligned}
& \frac{\sqrt{K_{a, m}}}{\sqrt{K_{a, w}}}=-0.43 x_{r}+1=a x_{r}+b, \\
& \frac{\mathrm{EC}_{b, m}}{\mathrm{EC}_{b, w}}=-0.67 x_{r}+1=c x_{r}+d,
\end{aligned}
$$

where $x_{r}$ is the ratio of sand layer thickness to the total thickness. $a, b, c$, and $d$ are coefficients that are dependent upon local geological conditions. The other symbols bear similar meaning as in the previous context.

Considering the dielectric constant of water is not significantly affected by the electrical conductivity under common application conditions [14]. The following procedures can be taken to determine the scour depth and sediment properties.

(1) Obtaining the calibration constants for (12) from simulated laboratory experiments or from the field data with known scour depth (step 0).

(2) Determining the bulk dielectric constant, $K_{a, m}$, from measured TDR signal (step 1, Figure 11).

(3) Determining the ratio of sediment layer to TDR probe length, $x$ (step 2, Figure 11).

(4) Estimating the scour depth, $S_{D}$, from $x_{r}$ (step 3, Figure 11).

A schematic plot of this procedure is shown in Figure 11.

\section{Theory and Application Procedure of the Ultrasonic Method for Scour Detection}

Ultrasonic waves are reflected at boundaries where there is a difference in the acoustic impedances of materials on either side of the boundary. The difference in acoustic impedance is commonly referred to as impedance mismatch. Generally the greater the impedance mismatch, the greater the percentage of energy that will be reflected at the interface or boundary between one medium and another. The reflection coefficient is given as

$$
R=\left(\frac{Z_{2}-Z_{1}}{Z_{2}+Z_{1}}\right)^{2}
$$

where $Z_{1}$ and $Z_{2}$ are acoustic impedance of materials on either side of a boundary.

The acoustic impedance $(Z)$ of a material is defined as the product of density $(\rho)$ and acoustic velocity $(V)$ of that material.

$$
Z=\rho V
$$

The application of ultrasonic method for scour detection is based on determining the time required for receiving the echo signal reflected from the water/sediment interface. The speed of a compression wave in water is $1482 \mathrm{~m} / \mathrm{s}$ at $20^{\circ} \mathrm{C}$, which corresponds to $1450 \times 10^{2} \mathrm{~g} / \mathrm{cm}^{2} / \mathrm{s}$ for the acoustic impedance. The acoustic impedance ranges from 2000 $4000 \times 10^{2} \mathrm{~g} / \mathrm{cm}^{2} / \mathrm{s}$ for silty clay to sandy gravel Hamilton [15]. As a result, the difference in acoustic impedance will cause appreciable reflections at the water/sediment interface. The location of the interface, which is a direct measure of scour depth, can be determined by analyzing the recorded ultrasonic signals.

\section{Laboratory Test for Comparing TDR Methods and Ultrasonic Methods}

5.1. Experiment Design. Figure 12 shows the experimental design for this study. Simulated scour/sedimentation tests were conducted in a cylindrical tank. The TDR probe was installed in the tank to acquire signals as sediments are added. Sediment materials were simulated by fine sand, coarse sand, and a mixture of coarse sand and gravel. The river conditions were simulated by controlling the electrical conductivity of water. The tank was first filled with water with specified salt concentration. Dry sediment material was then gradually poured into the tank. The water level was maintained constant by draining appropriate amount of water through the base of the tank. At each specified sand layer thickness, the amount of sand placed was recorded and used to calculate the density along with a TDR signal.

For comparison of TDR and ultrasonic methods, both the ultrasonic sensor and the TDR sensor were installed and connected to their respective electronics. The simulated sediment material consists of a mixture of coarse sand and gravel at $1: 1$ mass ratio. The tank was first filled with water of 500 ppm Sodium Chloride $(\mathrm{NaCl})$ salt concentration to a level just below the probe head. TDR and ultrasonic signals were obtained for each depth of the sediment deposit. This process proceeded until the mixture completely filled the tank. 


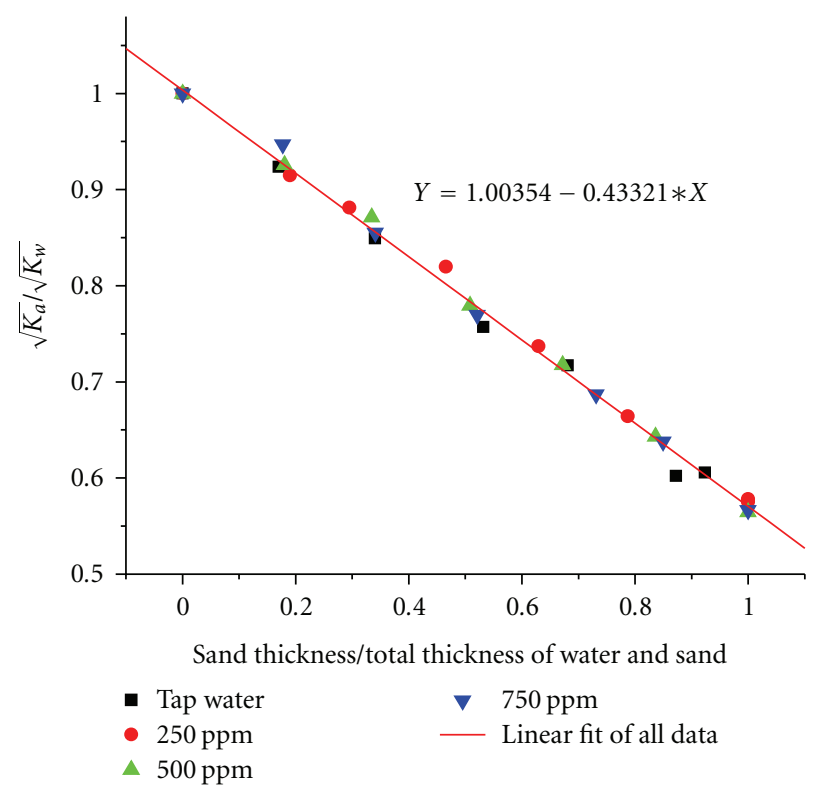

(a)

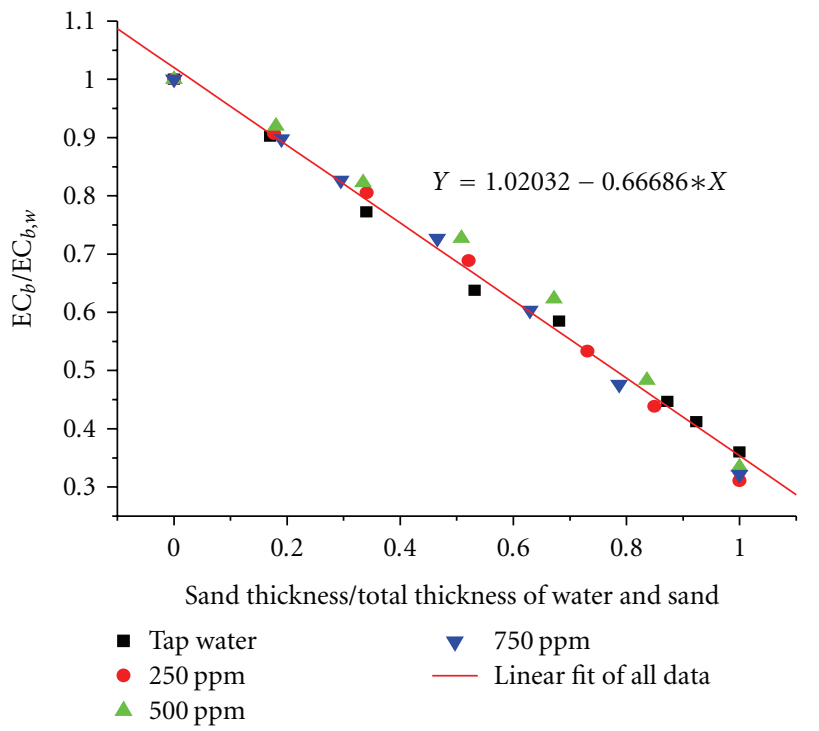

(b)

FIGURE 10: (a) Measured $\sqrt{ } K_{a}$ of sediment system normalized by that of water versus the normalized sediment thickness; (b) measured EC $b$ of sediment system normalized by that of water versus the normalized sediment thickness (sediment: fine sand).

Step 0: Obtaining the calibration constants $a$ and $b$ for (12) from laboratory simulated experiments

Step 1: Determining the bulk dielectric constant $K_{a, m}$ from TDR signal
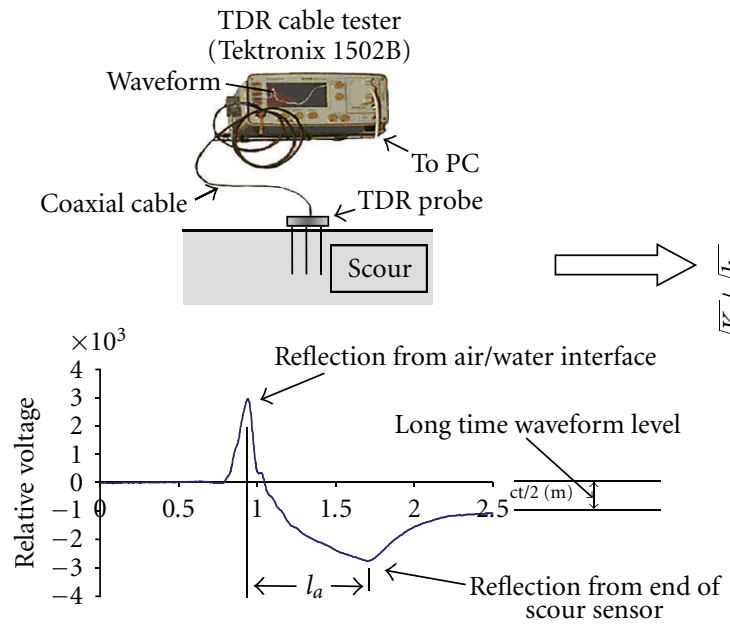

Step 2: Determining the ratio of sand layer/probe length from design equation
Step 3: Calculating scour depth

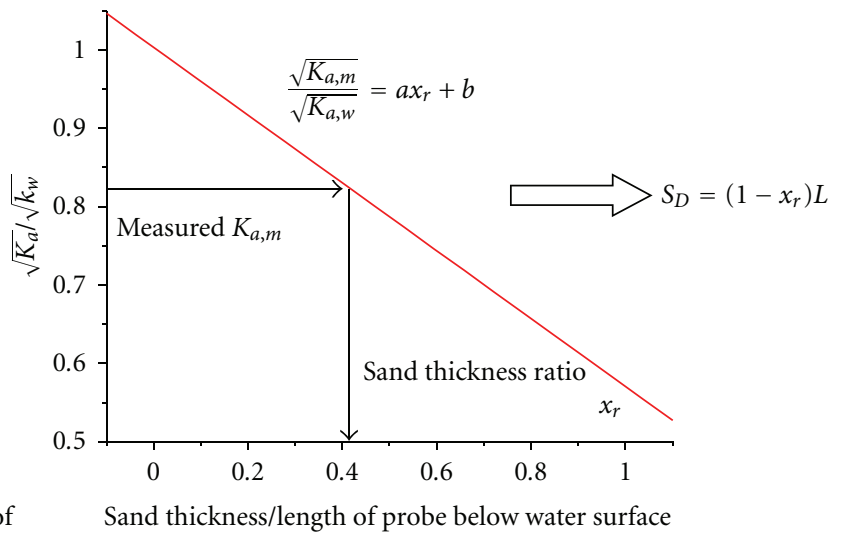

FIGURE 11: Procedures for estimating scour depth and river conditions.

Figure 13 shows variations of the TDR and ultrasonic signals with the thickness of sediment layer. As can be seen, both TDR signals and ultrasonic signals change in a predictable pattern.

5.2. Experiment Results and Analysis. The analysis of TDR signals followed the procedures outlined in the earlier part of this paper. The scour depths were directly estimated from the measured apparent dielectric constant. This constant was also used to estimate the dielectric constant of the sediment, from which the porosity and density were determined. The electrical conductivity measured from the same TDR signal was used to estimate the electrical conductivity of the water.

The analyses of ultrasonic measurements were based on the determination of the travel time required for the reflected 


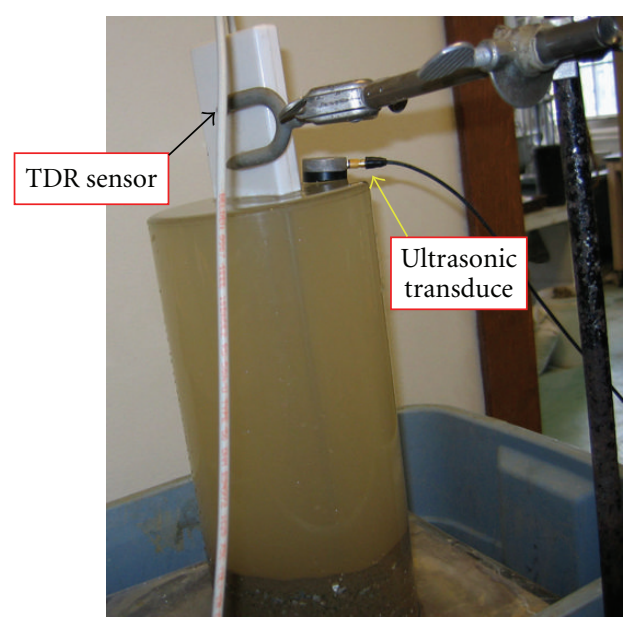

FIGURE 12: TDR probe, ultrasonic transducer, and the experimental tank.

signals. As shown in Figure 13(b), the travel time changes systematically with the distance to the water/sediment interface. The travel time was determined by picking the peaks in the recorded signal, representing the round trip travel time between ultrasonic transducer and surface of sediments. The distance of ultrasonic transducer to the surface of the sediment was then calculated by using the speed of ultrasonic wave in water.

5.3. Validation of the TDR Method. The developed algorithm for the TDR scour measurement system is evaluated by performing simulated scour experiments using a few other different types of sediment materials under different river conditions. The actual depths of scour were manually measured with a precise ruler. The results are summarized in Figure 14. The scour depth predicted by TDR algorithm described in this paper generally falls within $\pm 1.5 \mathrm{~cm}$ of actual measured values. This maps to an accuracy of $\pm 5 \%$ if normalized by the length of the TDR scour probe. The accuracy of guided EM wave TDR in determining the interface is not much affected by the length of the probe as long as the signal attenuation is prevented. This can be achieved with the use of a protective coating. It is anticipated that the relative error should reduce at longer TDR probe length.

\subsection{Measurement Accuracy of TDR versus Ultrasonic Methods.} Figure 15 shows an example where both TDR and ultrasonic methods are applied simultaneously during a simulated test. The results of direct measurement are used as baseline reference. The sediment material is a mixture of gravel and sand.

Two different equations are used for scour depth estimation by the TDR method. The first approach (denoted as TDR method (1) uses (5) which incorporates properties of a specific type of sediment. The second approach (denoted as TDR method (2) uses a general design equation (12) determined from a variety of sediment materials. A detailed comparison indicates that while results by either method should have sufficient accuracy for practical applications, the result of the TDR method 1 has slightly higher accuracy than that by those of method 2. There are two practical conclusions to be drawn from these observation: (1) A general equation format such as in (12) can be accurately applied for a wide range of sediment materials. (2) properties of local sediment materials can be used to refine (12) and thus further improve the accuracy of TDR scour predictions.

Comparison of the results of the TDR methods and the ultrasonic methods indicate that both methods can accurately estimate the scour depth but the trends of the change in the measurement accuracy are slightly different. Results from the TDR method are more accurate at larger scour depth. The ultrasonic method is more accurate for smaller scour depth. The observed increased accuracy of TDR is attributed to the improved accuracy in determining the reflection points for longer travel times. The observed trend of the change in the accuracy of the ultrasonic method is attributed to the fact that more attenuation and scattering of signal occur for longer distances. Comparatively, the higher measurement accuracy of the TDR methods with increasing scour depth is more desirable from a surveillance point of view since larger scour depths present a higher possibility of induced damage.

\subsection{Sediment Density and Electrical Conductivity of Water by} $T D R$. The electrical conductivity of water can be estimated from TDR measurements using (13). The results are shown in Figure 16 where they are compared with the direct measurement results obtained with an electrical conductivity meter. There is a reasonable match between the two.

The dry densities of sediments are estimated from TDR measurement according to step 5 of the application procedures previously described. In making the calculations, the dielectric constant of the soil solids $K_{a, s}$ is assumed to be 4 , and the specific gravity of the soil solids is assumed to be 2.65. The results are shown in Figure 17. Also shown in the figure is the dry density calculated from experimental records. The measured density of sediments by the TDR method closely matches that of the actual densities.

\subsection{Effects of Turbulence Conditions on TDR and Ultrasonic} Methods. The flood process generally brings about turbulent river conditions with a significant amount of air bubbles and suspended sediments. Experiments were completed to investigate the effects of air bubbles and sediments on TDR and ultrasonic methods. Figure 18 shows a photograph of the testing setup where air bubbles were generated at the bottom of the testing tank. The rate of air bubble generation was controlled from low to high levels to investigate its effects. Visual presentations of its effects on TDR and ultrasonic signals are shown in Figure 19. While air bubbles have negligible effects on the TDR signal quality, they show an important influence on the ultrasonic signals. The echo signal of the ultrasonic method is almost totally attenuated at high air bubble content. This is an important factor affecting 


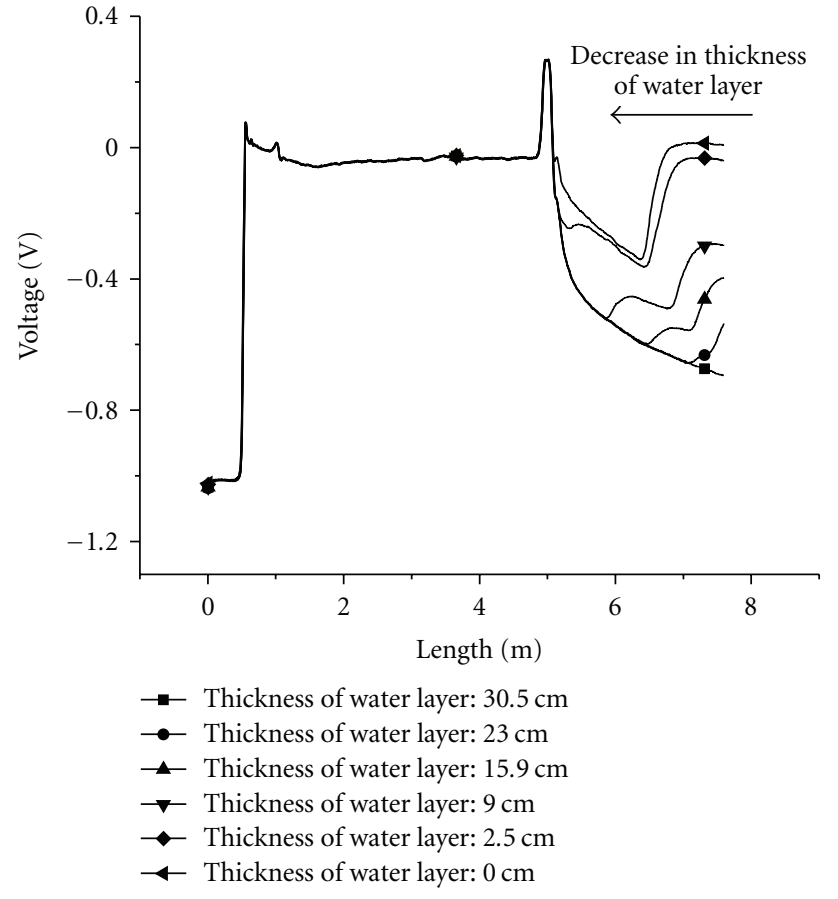

(a)
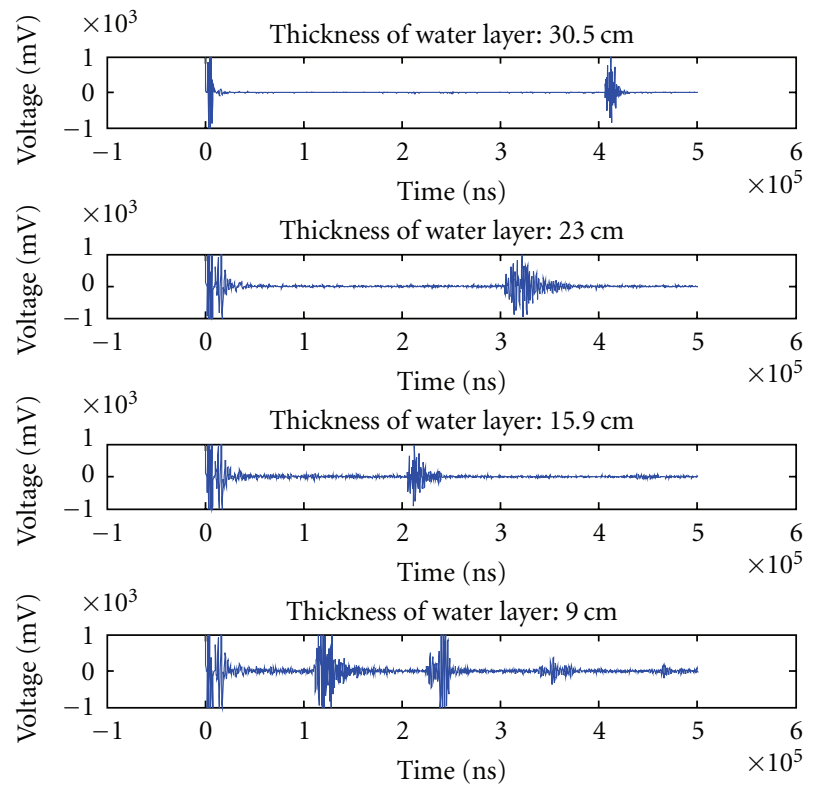

(b)

FigURE 13: (a) Variations of TDR signals with scour depth; (b) variations of ultrasonic signals with scour depth (sediment: coarse sand and gravel mixture).

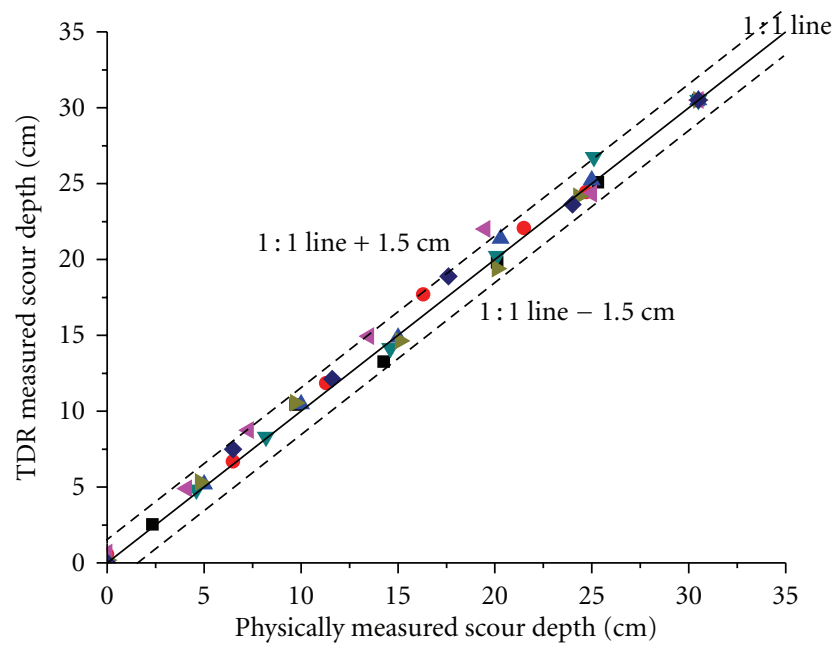

- Fine sand in tap water

- Fine sand in $250 \mathrm{ppm} \mathrm{NaCl}$ solution

- Fine sand in $500 \mathrm{ppm} \mathrm{NaCl}$ solution

$\nabla$ Fine sand in $750 \mathrm{ppm} \mathrm{NaCl}$ solution

$\checkmark$ Coarse sand in tap water

- Coarse sand in $500 \mathrm{ppm} \mathrm{NaCl}$ solution

- Washed coarse sand in $500 \mathrm{ppm} \mathrm{NaCl}$ solution

FIGURE 14: TDR measured thickness of sediment layer versus the actual thickness of sediment layer for various types of sediments and water conditions.

the reliability of the ultrasonic method for monitoring the scour during critical flood events. Similar effects were found for suspended solids.

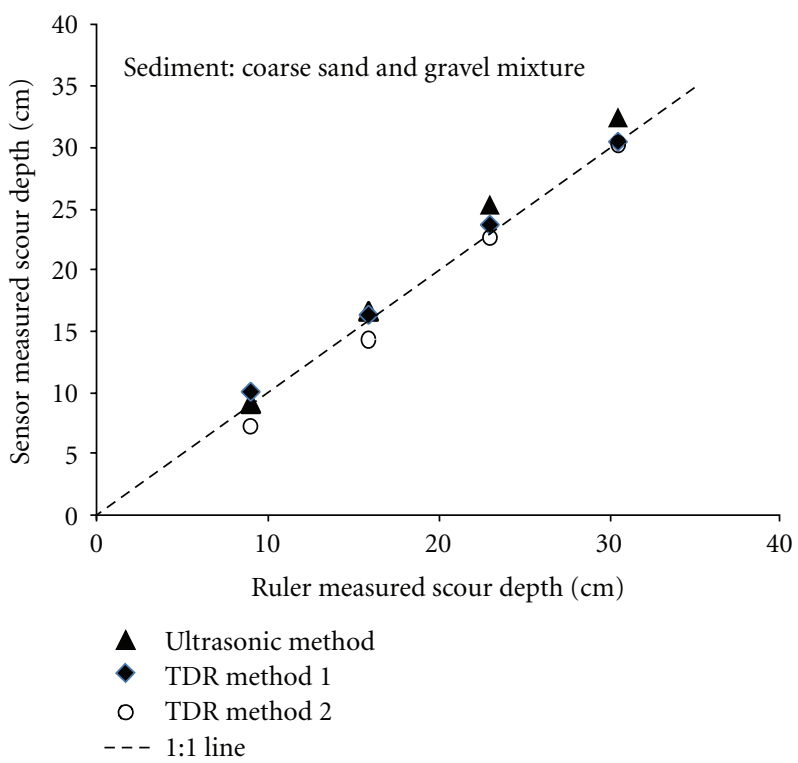

FIgURE 15: Prediction of scour depth using TDR and ultrasonic method (TDR method 1 uses (5); TDR method 2 uses (12)).

\section{Discussion}

This study indicates that both the TDR and ultrasonic methods can provide accurate measurements of scour depth. TDR system is advantageous in that it is inexpensive and amenable to automation. These are desirable features for 


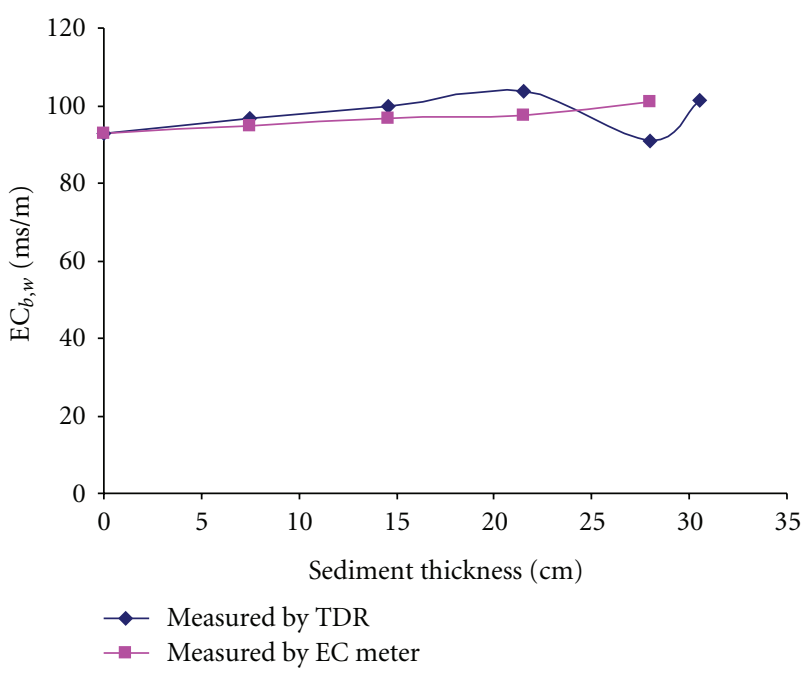

Figure 16: Prediction of electrical conductivity of water versus depth (sediment: coarse sand and gravel mixture).

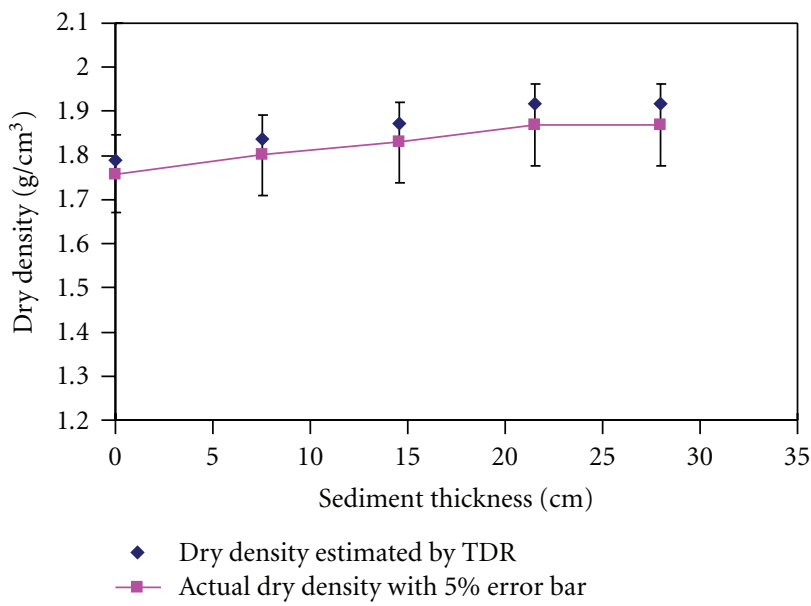

FIGURE 17: Sediment dry densities estimated by TDR at different scour depths (for a mixture of coarse sand and gravel at $1: 1$ mass ratio).

a real-time scour-monitoring and surveillance system. The ability of real-time surveillance is important since the most severe scour typically happens near the peak flood discharge. As sediments deposit in the scour hole during flood recession, post flood measurements might not truly describe the severity of the historical scour during the flooding process. The procedures introduced in this paper provide easy measurement of scour depth. Information about the sediment status (density) and water conditions (electrical conductivity) are obtained simultaneously. These could be used to enable a mechanistic understanding of scour phenomena. The accuracy of TDR can be affected by the electromagnetic interference and signal attenuation in the cable length. This requires careful planning for deployment of the system in the field. In addition, TDR

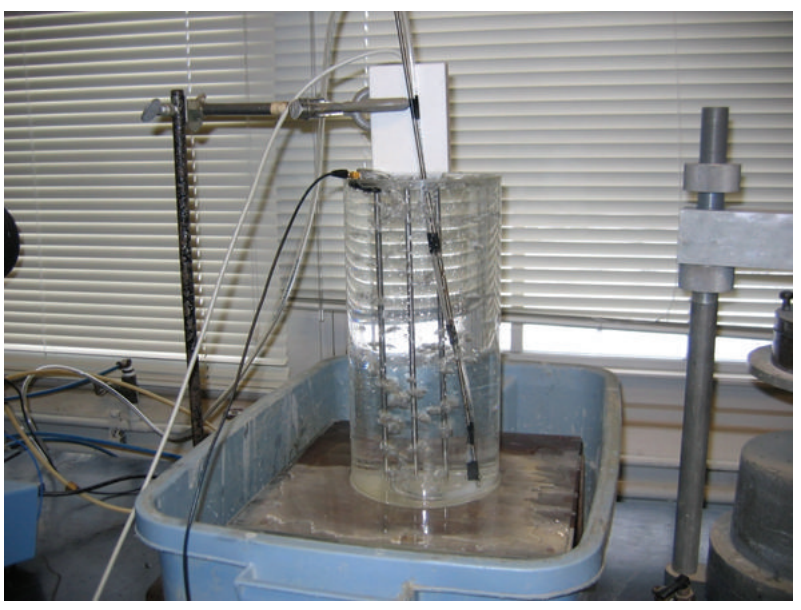

FIGURE 18: Generation of air bubble to evaluate its effects on TDR and ultrasonic measurement.

sensors only measure scour at a given point. Multiple TDR probes will be needed to map the shape of the scour hole. A protective coating will be needed to prevent TDR wave signal attenuation for a long TDR scour probe. Potential ways to protect the TDR probe from impacts of debris, include to submerge the probe completely under the water, to place the TDR probe in locations that is less likely to be accessed by debris, and to use a strong supporting element. As mentioned in the introduction section of this paper, the TDR probe developed by Yankielun and Zabilansky [3] has been installed in the field for years and survived flood debris and ice loading. In the authors opinion, the potential impacts of debris can be reduced; however, such impacts might be hard to be completely prevented. The ultrasonic method is valuable for post-event scour measurements. It requires the ultrasonic transducer to be maintained below the water level and provide a local measurement. However, as it is a nonintrusive technology, ultrasonic transducers can be moved to determine the shape of river bed after scour event. The interpretation of ultrasonic signals can be challenging, especially for complex river beds. There could be a significant amount of background noise in the ultrasonic signal caused by air bubbles and suspended solids in the water, that severely affect the identification of the reflected signal.

\section{Conclusion}

This paper introduces a new scour measurement method based on TDR technology. This method is robust and utilizes simple analysis procedures. Preliminary results show that it provides accurate measurement of scour depth (sediment thickness), density of sediments, and electrical conductivity of river water. A comparative study of TDR and the ultrasonic method for scour measurements is also described. It is found that both TDR and ultrasonic methods can accurately measure the scour depth; however, more information about status of sediments and water can be 


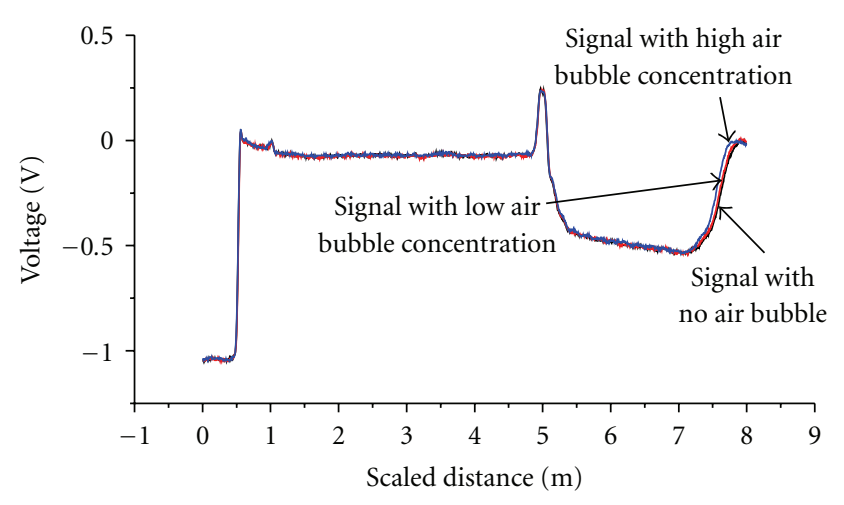

(a)

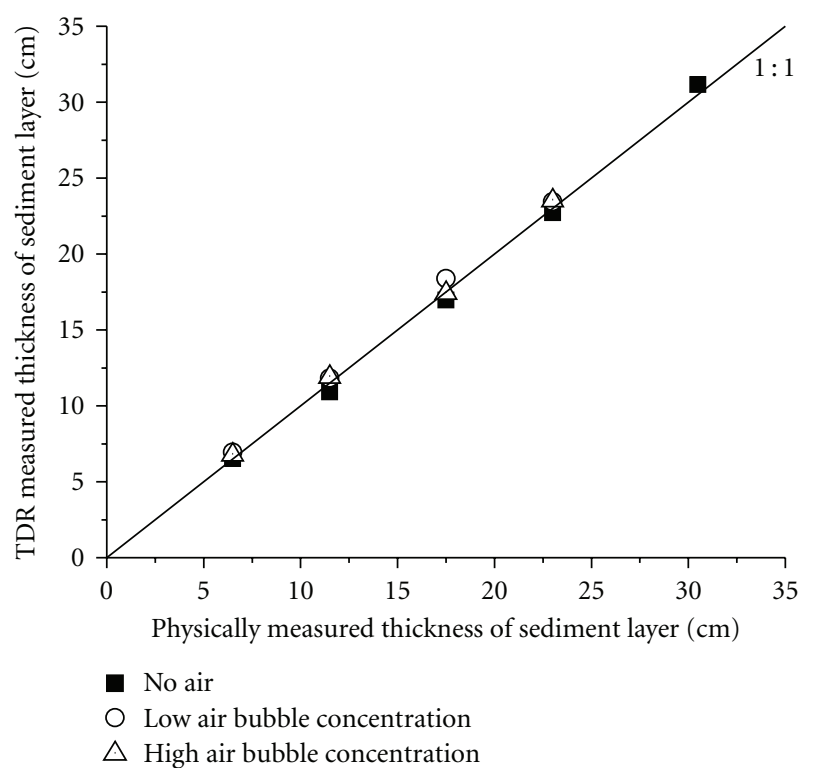

(b)
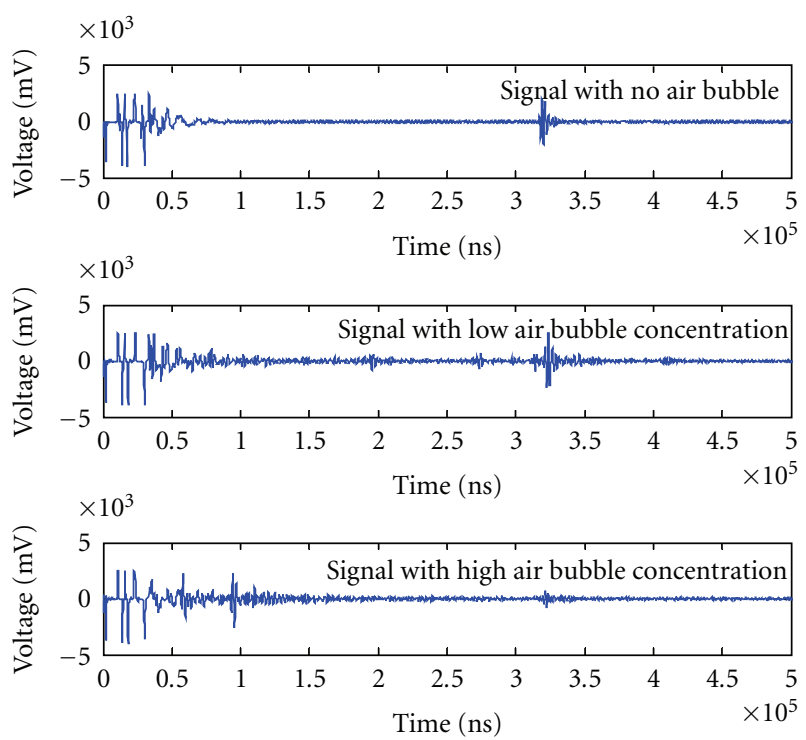

(c)

Figure 19: Effects of air bubble on (a) TDR signals, (b) TDR scour depth estimation, and (c) Ultrasonic Signals.

obtained from TDR measurements. Experiments indicate that TDR is less influenced by turbulent conditions that result in suspended solids, air bubbles, and fast flowing water, which are typical of flood processes. TDR-monitoring systems are rugged and can provide real-time surveillance. The data they collect on scour evolution during major floods will help examine the various scour mechanisms. Ultrasonic methods, on the other hand, can be a useful tool to rapidly measure the scour contour. On-site monitoring with TDR method in conjunction with postflood survey with ultrasonic methods will enable accurate determination of the status of bridge scour during and post major flood events to help ensure the long-term safety of bridge structures.

\section{List of Notations}

$K_{a}$ : Measured dielectric constant

$L_{p}: \quad$ Physical length of probe in testing materials

$L_{a}$ : Apparent length of probe in testing materials

$\theta: \quad$ Volumetric water content

$V_{s}$ : Source voltage

$V_{f}:$ Long-term voltage level

C: A constant related to probe configuration

$K_{a, w}$ : Dielectric constant of water

$K_{a, b s}$ : Dielectric constant of bulk sand (sand with water mixture)

$K_{a, m}$ : Measured bulk dielectric constant

$L_{1}:$ Thickness of water layer 
$L_{2}$ : Thickness of sand layer

L: $\quad$ Total thickness of sand and water layer

$x$ : Thickness of sand (sediment) layer

$\mathrm{EC}_{b, w}$ : Water conductivity

$k_{a, s}: \quad$ Dielectric constant of soil solid

$\mathrm{EC}_{b, b s}$ : Electrical conductivity of saturated sand layer

$\mathrm{EC}_{b, m}$ : Measured overall electrical conductivity

$F$ : $\quad$ Formation factor

$f: \quad$ Form factor

$x_{r}$ : $\quad$ Ratio of sand thickness to the total thickness of water and sand

$R: \quad$ Reflection coefficient

$Z$ : $\quad$ Acoustic impedance

$\rho: \quad$ Density

$V: \quad$ Acoustic velocity.

\section{References}

[1] Modjeski and Masters, August 2006, http://www.modjeski .com/.

[2] C. H. Dowding and C. E. Pierce, "Use of time domain reflectometry to detect bridge scour and monitor pier movement," in Proceedings of the Symposium and Workshop on Time Domain Reflectometry in Environmental, Infrastructure, and Mining Applications, pp. 579-587, Northwestern University, Evanston, Ill, USA, 1994.

[3] N. E. Yankielun and L. Zabilansky, "Laboratory investigation of time-domain reflectometry system for monitoring bridge scour," Journal of Hydraulic Engineering, vol. 125, no. 12, pp. 1279-1284, 1999.

[4] E. V. Richardson and S. R. Davis, Evaluating Scour at Bridges, Hydraulic Engineering Circular, no. 18, FHWA NHI 01-001, U.S. Department of Transportation, Washington, DC, USA, 4th edition, 2001.

[5] P. F. Lagasse, E. V. Richardson, J. D. Schall, and G. R. Price, "Instrumentation for measuring scour at bridge piers and abutments," NCHRP Report 396, 1997.

[6] B. E. Hunt, "Practices for monitoring scour critical bridges," NCHRP Project, First Draft Report 20-5, Transportation Research Board, National Research Council, National Academy Press, Washington, DC, USA, 2005.

[7] X. Yu and J. L. Zabilansky, Time Domain Reflecometry for Automated Bridge Scour Monitoring, ASCE Geotechnical Special Publications, GeoShanghai, Shanghai, China, 2006.

[8] X. B. Yu and X. Yu, "Time domain reflectometry automatic bridge scour measurement system: principles and potentials," Structural Health Monitoring, vol. 8, no. 6, pp. 463-476, 2009.

[9] Campbell Scientific, Inc., TDR100 User Manual, Campbell Scientific, Inc., Logan, Utah, USA, 2008, http://www .campbellsci.com/documents/manuals/tdr100.pdf.

[10] K. L. Rens, T. J. Wipf, and F. W. Klaiber, "Review of nondestructive evaluation techniques of civil infrastructure," Journal of Performance of Constructed Facilities, vol. 11, no. 4, pp. 152-160, 1997.

[11] X. B. Yu and X. Yu, "Scour measurement by time domain reflectometry," in Proceedings of the 3rd International Symposium and Workshop on Time Domain Reflectometry for Innovative Soils Applications (TDR '06), Purdue University West Lafayette, West Lafayette, Ind, USA, September 2006.
[12] J. R. Birchak, C. G. Gardner, J. E. Hipp, and J. M. Victor, "High dielectric constant microwave probes for sensing soil moisture," Proceedings of the IEEE, vol. 62, no. 1, pp. 93-98, 1974.

[13] G. E. Archie, "The electrical resistivity log as an aid in determining some reservoir characteristics," Petroleum Transactions of the AIME, vol. 146, pp. 54-61, 1942.

[14] X. Yu and V. P. Drnevich, "Soil water content and dry density by time domain reflectometry," Journal of Geotechnical and Geoenvironmental Engineering, vol. 130, no. 9, pp. 922-934, 2004.

[15] E. L. Hamilton, "Reflection coefficients and bottom glasses at normal incidence computed from Pacific sediment properties," Geophysics, vol. 35, pp. 995-1004, 1970. 

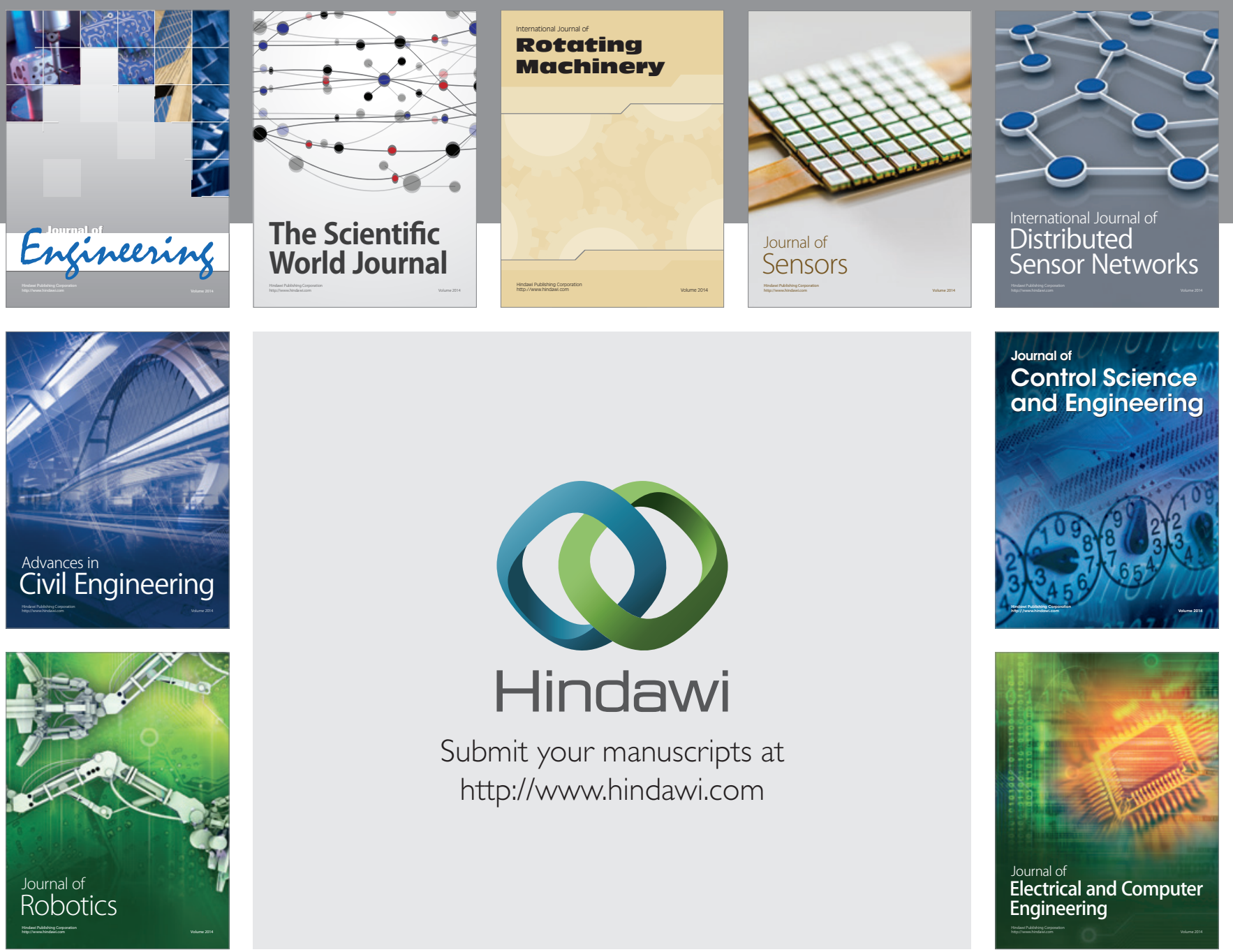

Submit your manuscripts at

http://www.hindawi.com
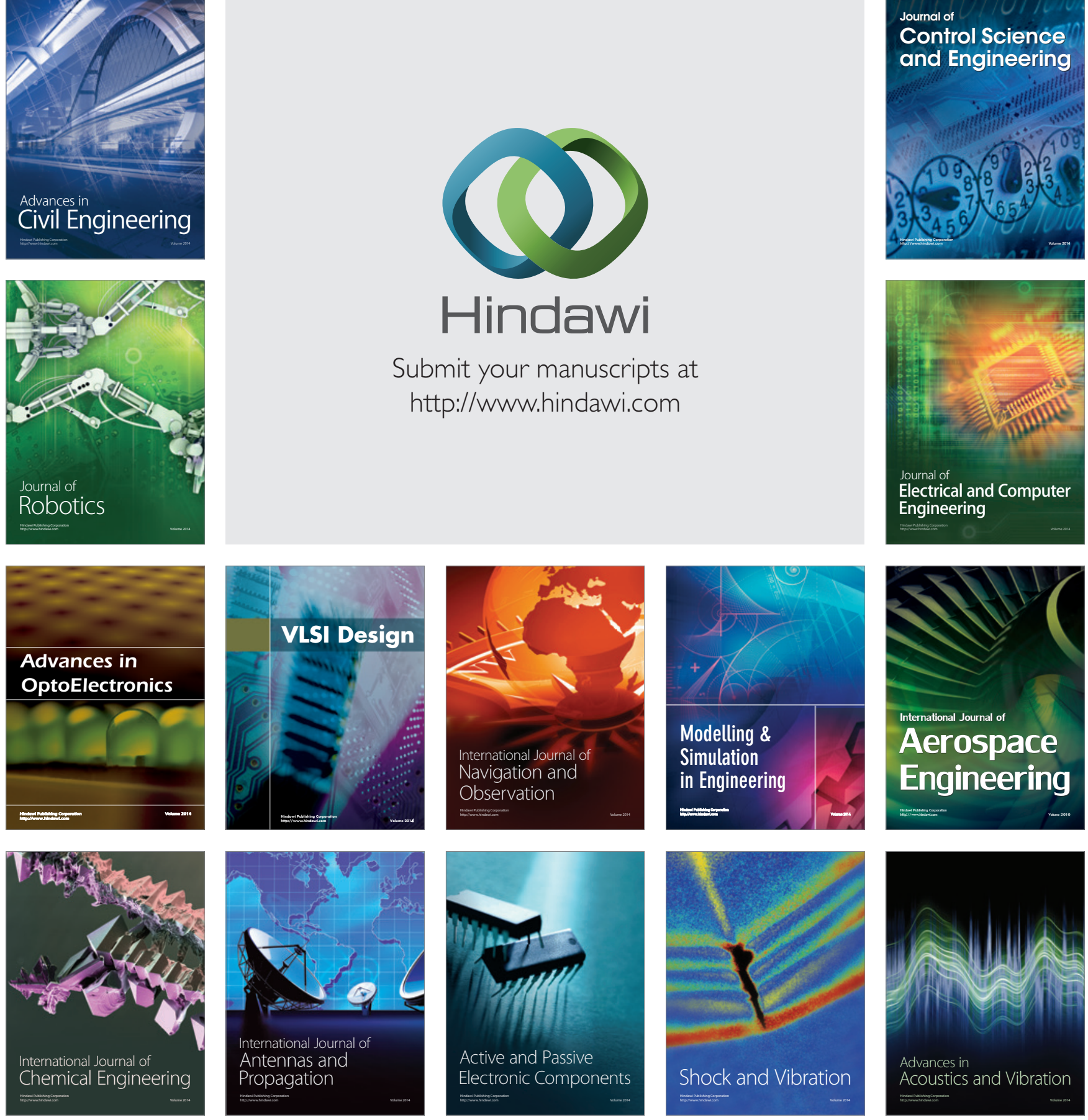